\title{
Effectiveness of epidural and systemic postoperative analgesia in laparoscopic urologic surgery - A retrospective cohort study
}

\author{
Conchita Monsalve ${ }^{1}$, Ana Bogdanovich ${ }^{1}$, Laura Izquierdo ${ }^{2}$, Clara Hernández-Cera ${ }^{1}$, Carme Busquets ${ }^{1}$ and Sebastián Videla ${ }^{3 *}$ \\ ${ }^{1}$ Department of Anesthesiology, Hospital Clinic. Universitat de Barcelona, Spain \\ ${ }^{2}$ Department of Urology, Hospital Clinic. Universitat de Barcelona, Spain \\ ${ }^{3}$ Department of Experimental and Health Sciences. Faculty of Health and Life Sciences, Universitat Pompeu Fabra, Spain
}

\begin{abstract}
Aim: To assess the effectiveness of epidural and systemic postoperative analgesia in laparoscopic urologic surgery.

Patients and methods: Retrospective cohort of patients submitted to laparoscopic urological surgery: nephrectomy (LN) or prostatectomy (LP). Two protocols of analgesia for laparoscopy surgery were used: epidural Patient Controlled Analgesia of Ropivacaine and Fentanyl (epidural group) and subcutaneous-methadone and intravenous-NSAIDs (systemic group). The analgesic effectiveness at rest was evaluated at 24 and 48 h as the worst pain intensity in the previous 24 hours (NRS: 0 to 10) for each evaluation. Rescue analgesia and presence of nausea/vomiting were also assessed.

Results: Between January-2009 and December-2010, 414 consecutive patients were included: 290 LN (139 males, 151 females) and 124 LP. The median (sd) age was 61 (12) year-old.

No differences were found respect to the mean (sd) of the worst pain intensity at 24 and 48 hours in LN population between epidural [1,1(1,1); $0,9(1,0)]$ and systemic $[1,2(1,2) ; 1,2(1,1)]$ groups. In LP population similar results were observed [epidural: 1,0(0,8);0,9(0,9); systemic: $0,8(1,1) ; 1,1(1,2)]$.

With regard to rescue medication, no differences among populations were observed. The overall nausea/vomiting was lower than $5 \%$.

Conclusion: Our results suggest that in laparoscopic urological surgery no differences in post-operative analgesia were observed between epidural PCA (Ropivacaine and Fentanyl) and systemic (combination of sc-methadone and iv-NSAIDs) groups. Epidural analgesia in laparoscopy urological surgery should be reconsidered.
\end{abstract}

\section{Introduction}

Postoperative pain is an important health-care issue. As a matter of fact, pain after post-urological surgery is one of the more frequent causes of delayed discharge with respect to these patients. New laparoscopic techniques have provoked a dramatic change in urological surgery and in their co-morbidities like pain $[1,2]$. Minimally invasive surgery is related to the early recovery of the patient, to a rapid incorporation into normal life with consequent cost reduction, to better cosmetic results and to less acute postoperative pain [1-3].

In parallel to the introduction of the laparoscopic techniques, the postoperative analgesia protocols have been modified. Nowadays, multimodal analgesia is a common practice in the management of our patients [3-5]. All these approaches have allowed improving postoperative comfort of the patients and early discharge from hospital. However, in spite of these improvements, postoperative pain remains incompletely controlled, and protocols to manage the postoperative pain after urological surgery are not standardized [6-8]. Therefore, to provide data on the real benefits of analgesia protocols for acute postoperative pain should help the urologist in their clinical practice. The aim of this study was to assess the effectiveness of epidural and systemic postoperative analgesia in laparoscopic urologic surgery at 48 hours after surgery.

\section{Patients and methods}

\section{Study design}

A single-center, retrospective cohort study, based on a prospectively compiled database from clinical practice of patients' submitted to laparoscopic urologic surgery and treated. The study was reviewed and approved by the hospital's independent ethics committee. Before the laparoscopic surgery all patients gave their written informed consent for their medical information to be used for purposes of scientific research in accordance with the Ethical Committee of the participating site. This study was performed according to the stipulations made in the Declaration of Helsinki, and the level of protection of confidentiality concerning personal data was ensured as required by the Spanish law (LOPD 15/1999).

Correspondence to: Sebastián Videla, Department of Experimental and Health Sciences, Faculty of Health and Life Sciences. Universitat Pompeu Fabra, Dr. Aiguader 80, 08003, Barcelona, Catalonia, Spain, Tel: 0034-609-059-287, E-mail: svidela@esteve.es

Key words: epidural analgesia, systemic analgesia, laparoscopic urologic surgery

Received: January 12, 2016; Accepted: February 01, 2016; Published: February 05,2016 


\section{Study population}

The patients included had to fulfill the following eligibility criteria: men or women, $\geq 18$ years-old, submitted to nephrectomy or prostatectomy laparoscopic surgery. The inclusion period was between January 2009 and December 2010. At our hospital, the epidural postoperative analgesic protocols were revised and updated in 2008 and implemented in January 2009, therefore that month was considered the starting point of the study.

The following data were gathered: age, sex, operative risk by means of American Society of Anesthesiologist (ASA) classification, diagnosis, pain intensity, rescue analgesia (concomitant pain medications different from postoperative analgesic protocols or analgesic medication included in the protocol but administered in higher doses), presence of nausea and vomiting (PONV) and other adverse events related to the analgesic protocols.

\section{Post-operative analgesic protocols}

Two protocols were used: epidural and systemic (non-epidural), which were applied during the 48 hours after the laparoscopy.

Epidural analgesic protocol: epidural catheter and patientcontrolled-analgesia (PCA) of $0.16 \%$ ropivacaine and $2 \mu \mathrm{g}$ fentanyl.

Systemic (Non-epidural) analgesic protocol: subcutaneous methadone (4-5 mg/8 hour of methadone hidrocloruro and $1 \mathrm{~g} / 8$ $\mathrm{h}$ of paracetamol intravenous or $50 \mathrm{mg} / 8$ hour of desketoprofen intravenous, depending on renal function.

Two anesthesiologists took care of the anesthetic procedures. One of them always applied the epidural analgesia, and the other one always applied the systemic analgesia, according to the protocols. Therefore, the assignation of the patients to the postoperative analgesic protocols depended on the anesthesiologist in charge.

\section{Postoperative pain effectiveness evaluation}

The postoperative effectiveness was assessed by another anesthesiologist from the Acute Pain Unit. The postoperative pain intensity (the worst pain intensity in the previous 24 hours evaluated by a Numerical-Pain-Rating-Scale: '0' for no pain in the past 24 hours, and ' 10 ' for the worst possible pain in the past 24 hours) was evaluated at 24 and 48 hours after the surgery. Likewise, after measuring the pain intensity, the patient was asked about adverse events. Every day this anesthesiologist reviewed the rescue analgesic medication requirements and the adverse events gathered in the medical file.

\section{Statistical analysis}

The sample size was defined as all patients operated by laparoscopic during the inclusion period.

A descriptive analysis was performed for baseline population characteristics. Continuous variables were described as mean (standard deviation), and categorical data were summarized as absolute frequency and percentages. Responder ('treatment success') was defined as the patient who did not need rescue medication. The percentage of patients who had a NRPS $<3$ over the 48 hours after surgery were calculated. An exploratory analysis to compare both analgesic protocols was carried out ( $t$-test for quantitative variables, $\chi^{2}$ test for qualitative variables). Data analysis was carried out using SPSS version 12.0 statistical software (Chicago, Illinois, USA).

\section{Results}

\section{Patient characteristics}

A total of 414 consecutive patients, who fulfilled the inclusion criteria, were included. Table 1 shows the baseline characteristics and the follow chart according to laparoscopic urologic surgery in Figure 1. The anesthetic management was similar in all patients included.

\section{Effectiveness of postoperative analgesic protocols}

All patients followed the postoperative analgesic protocols assigned. Table 2 shows the pain intensity at 24 and 48 hours, and rescue medication at 48 hours after surgery. No statistically significant differences between analgesic postoperative protocols were observed. Likewise, similar results were obtained regarding the percentage of responders. Nevertheless, the rescue medication requirements were lower in laparoscopic prostatectomy [2\% (3/124)] in comparison to laparoscopic nephrectomy [10\% (28/290)], p=0.010. No differences between analgesic protocols were observed in the percentage of patients who had a NRPS $<3$ over the 48 hours after surgery.

\section{Adverse events}

The only adverse events collected and related to analgesic protocols were nausea and vomiting (Table 2). The overall PONV was lower than $5 \%$. No differences were observed between analgesic postoperative protocols.

Table 1. Baseline characteristics of all patients included $(n=414)$.

\begin{tabular}{|c|c|c|c|c|}
\hline \multirow[t]{4}{*}{ Baseline characteristics } & \multicolumn{4}{|c|}{ Laparoscopic Urologic Surgery } \\
\hline & \multicolumn{2}{|c|}{ Nephrectomy } & \multicolumn{2}{|c|}{ Prostatectomy } \\
\hline & epidural & systemic & epidural & systemic \\
\hline & $\mathrm{n}=171$ & $\mathrm{n}=119$ & $\mathrm{n}=72$ & $\mathrm{n}=52$ \\
\hline \multicolumn{5}{|l|}{ Age } \\
\hline Mean years (SD) & $58(13)$ & $58(14)$ & $63(5)$ & $63(6)$ \\
\hline \multicolumn{5}{|l|}{ Sex } \\
\hline Male $[\mathrm{n},(\%)]$ & $76(44 \%)$ & $63(53 \%)$ & $72(100 \%)$ & $52(100 \%)$ \\
\hline Female $[\mathrm{n},(\%)]$ & $95(56 \%)$ & $56(47 \%)$ & $-(-)$ & $-(-)$ \\
\hline \multicolumn{5}{|l|}{ ASA classification: } \\
\hline $\mathrm{I}[\mathrm{n},(\%)]$ & $32(19 \%)$ & $17(14 \%)$ & $27(38 \%)$ & $18(35 \%)$ \\
\hline II [n, (\%)] & $99(58 \%)$ & $84(71 \%)$ & $39(54 \%)$ & $26(50 \%)$ \\
\hline III [n, (\%)] & $37(22 \%)$ & $12(10 \%)$ & $6(8 \%)$ & $8(15 \%)$ \\
\hline IV $[\mathrm{n},(\%)]$ & $3(2 \%)$ & $6(5 \%)$ & 0 & 0 \\
\hline
\end{tabular}

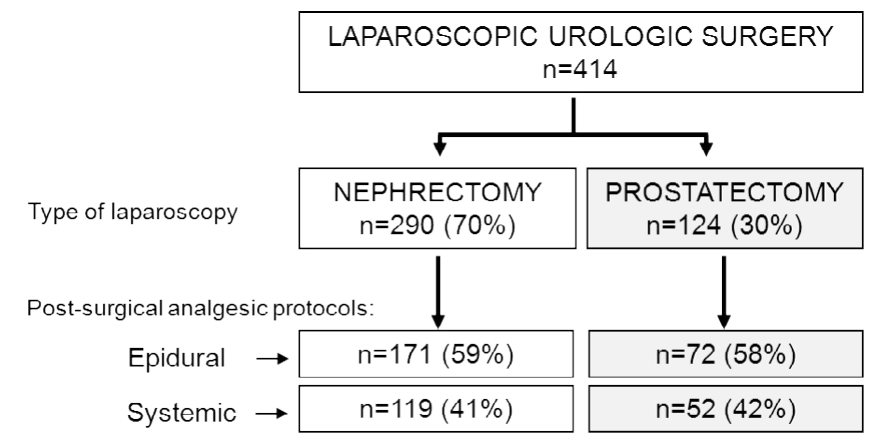

Epidural: epidural catheter and patient-controlled analgesia of ropivacaine and fentanyl Systemic (non-Epidural): subcutaneous methadone and paracetamol or dexketoprofen intravenous 
Table 2. Pain intensity (numerical rating pain scale from 0 to 10 ) at 24 and 48 hours, recue medication at 48 hours and adverse events at 48 hours after the laparoscopic surgery.

\begin{tabular}{|c|c|c|c|c|}
\hline & \multicolumn{4}{|c|}{ Laparoscopic Urologic Surgery } \\
\hline & \multicolumn{2}{|c|}{ Nephrectomy } & \multicolumn{2}{|c|}{ Prostatectomy } \\
\hline & Epidural $^{1}$ & Systemic $^{2}$ & Epidural $^{1}$ & Systemic $^{2}$ \\
\hline & $\mathrm{n}=171$ & $\mathrm{n}=119$ & $\mathrm{n}=72$ & $\mathrm{n}=52$ \\
\hline \multicolumn{5}{|l|}{ Effectiveness } \\
\hline \begin{tabular}{|c|} 
Pain intensity at \\
$24 \mathrm{~h} / 48 \mathrm{~h}[\mathrm{~m}(\mathrm{sd})]$
\end{tabular} & $1,1(1,1) / 0,9(1,0)$ & $1,2(1,2) / 1,2(1,1)$ & $1,0(0,8) / 0,9(0,9)$ & $0,8(1,1) / 1,1(1,2)$ \\
\hline $\operatorname{Responder}^{3}[\mathrm{n}(\%)]$ & $156(91)$ & $106(89)$ & $71(99)$ & $50(96)$ \\
\hline \multicolumn{5}{|l|}{ Adverse Events } \\
\hline Nausea $[\mathrm{n}(\%)]$ & $8(5 \%)$ & $5(4 \%)$ & $1(1 \%)$ & $2(4 \%)$ \\
\hline Vomiting [n (\%)] & $7(4 \%)$ & 0 & 0 & $1(2 \%)$ \\
\hline
\end{tabular}

${ }^{1}$ Epidural: epidural catheter and patient-controlled analgesia of ropivacaine and fentanyl

${ }^{2}$ Systemic (Non-Epidural): subcutaneous methadone and paracetamol or dexketoprofen intravenous

${ }^{3}$ Responder: patients who did not need analgesic rescue medication

\section{Discussion}

To date, limited data on the efficacy or the effectiveness of postoperative analgesia in laparoscopic urologic surgery are available [2]. Currently, postoperative analgesia depends on each hospital, each type of surgery and the patient co-morbidities. Ideally, a good postoperative analgesic protocol should maintain the pain intensity close to cero during the post-surgery period, it should be safe for the patients (with minimum adverse events) and it should have a reasonable cost [5,7-11].

Epidural analgesia in laparoscopic urological surgery is not without controversy [2]. In this study, the effectiveness of the epidural analgesia based on an epidural catheter and a PCA of ropivacaine and fentanyl on postoperative pain intensity was similar to systemic analgesia based on subcutaneous methadone plus intravenous NSAIDs in laparoscopy surgery. Likewise, similar results were found with respect to the percentage of patients who needed rescue medication and in the adverse event profile. Although we have not observed any complications arising from the placement of an epidural catheter, this procedure is generally not exempt from complications [2]. Focused on laparoscopy surgery, several considerations as to the use of PCA have been made [12]: 1) the dose of the PCA bolus should not always meet the patients' needs; 2) not all patients want to depend on the PCA; 3) the PCA might be wrongly handled due to the fear of misinformation; 4) lack of support from the nurses, etc. In the case of a malfunction of the PCA, an anesthesiologist or an expert is required. The PCA is not recommended to patients with a cognitive impairment as the self-administration cannot be effective. On the other hand, family or nurses may take the control of the PCA. Face with the lack of clinical trials, our results suggest that it would seem reasonable to reconsider epidural analgesia in laparoscopic urologic surgery and that it should be reserved for open surgery procedures.

In line with other authors, side effects different from nausea and vomiting and related to the use of morphine or local anesthetics administered by epidural route were not reported $[13,14]$. In contrast, the overall percentage of PONV was much lower than previously reported [15-17]. An explanation for these results might be that all patients received dexamethasone $(4 \mathrm{mg})$ at the beginning of surgery and ondansetron $(8 \mathrm{mg})$ at the end.

There are several limitations to this study, which should be considered before drawing any conclusions. The study design, not randomized, might underestimate or overestimate the generalizability of the results beyond the population and conditions studied. In fact, this study was planned as an exploratory one based on the clinical practice. Likewise, the sample size might also underestimate or overestimate the generalizability of the results, mainly in open prostatectomy. The evolution of the postoperative pain was only assessed twice (at 24 and 48 hours). At the same time, when the study was planned, it was thought that the moment of pain intensity control could not be well standardized. In order to minimize the effect of the variability with regard to the moment of taking the pain intensity, it was done in the moment of the worst pain in the previous 24 hours. Consequently, since this study is based on clinical practice, this could lead to underestimating the effectiveness considering the clinical trial results. In spite of this, the results of our study suggest that the analgesic protocols are not difficult types of treatment to manage the postoperative pain. Clinical trials are necessary to validate the efficacy of these analgesic protocols. The adverse events post-surgery related to analgesic protocols were mainly gathered by interview in the daily controls. Therefore, the number and intensity of adverse events could be underestimated.

In this study, i.e. in laparoscopy surgery, the effectiveness of the epidural analgesic protocol (epidural catheter and PCA of ropivacaine and fentanyl) on postoperative pain intensity and rescue medication requirements were similar to systemic analgesia (subcutaneous methadone plus intravenous NSAIDs). Furthermore, all analgesic postoperative protocols were well tolerated. Therefore, epidural analgesia in laparoscopic urologic surgery should be reconsidered. This type of postoperative analgesia might be mainly indicated for open urological surgery. Clinical trials (and pharmacoeconomic studies) are required to validate these results.

\section{Conflict of interest}

SV has received honoraria for collaborating with Laboratorios Dr. Esteve working in the pain area. The remaining authors have no conflict of interest to declare.

\section{Acknowledgements}

Special thanks go to the patients from Urological Surgery Unit.

\section{References}

1. Levy BF, Scott MJ, Fawcett WJ, Day A, Rockall TA (2011) Optimizing patient outcomes in laparoscopic surgery. Colorectal Dis 13 Suppl 7: 8-11. [Crossref]

2. Conacher ID, Soomro NA, Rix D (2004) Anaesthesia for laparoscopic urological surgery. Br J Anaesth 93: 859-864. [Crossref]

3. Vadivelu N, Mitra S, Narayan D (2010) Recent advances in postoperative pain management. Yale J Biol Med 83: 11-25. [Crossref]

4. Breivik H, Stubhaug A (2008) Management of acute postoperative pain: still a long way to go! Pain 137: 233-234. [Crossref]

5. Rosenquist RW, Rosenberg J; United States Veterans Administration (2003) Postoperative pain guidelines. RegAnesth Pain Med 28: 279-288. [Crossref]

6. Wu CL, Raja SN (2011) Treatment of acute postoperative pain. Lancet 377: 22152225. [Crossref]

7. Viscusi ER (2005) Emerging techniques in the management of acute pain: epidural analgesia. Anesth Analg 101: S23-29. [Crossref]

8. Gray A, Kehlet H, Bonnet F, Rawal N (2005) Predicting postoperative analgesia outcomes: NNT league tables or procedure-specific evidence? Br J Anaesth 94: 710714. [Crossref]

9. White PF, Kehlet H (2010) Improving postoperative pain management: what are the unresolved issues? Anesthesiology 112: 220-225. [Crossref] 
10. Rowlingson JC (2005) Postoperative pain: to diversify is to satisfy. Anesth Analg 101: S1-4. [Crossref]

11. RecartA, Duchene D, White PF, Thomas T, Johnson DB, et al. (2005) Efficacy and safety of fast-track recovery strategy for patients undergoing laparoscopic nephrectony. J Endourol 19: 1165-1169. [Crossref]

12. Grass JA (2005) Patient-controlled analgesia. AnesthAnalg101: S44-61. [Crossref]

13. Villalonga A, Gomar C, Nalda MA (1989) [Effect of the peridural methadone concentration in postoperative analgesia]. Rev EspAnestesiolReanim 36: 260-263. [Crossref]

14. Parramon F, GarcíaCh, Gambús P, Vilaplana J, Aragonés N, et al. (2003) [Postoperative patient-controlled analgesia is more effective with epidural methadone than with intravenous methadone in thoracic surgery]. Rev Esp Anestesiol Reanim 50: 326-331. [Crossref]

15. Apfel CC, Korttila K, Abdalla M, Kerger H, Turan A, et al. (2004) A factorial trial of six interventions for the prevention of postoperative nausea and vomiting. $N$ Engl J Med 350: 2441-2451. [Crossref]

16. Chatterjee S, Rudra A, Sengupta S (2011) Current concepts in the management of postoperative nausea and vomiting. Anesthesiol Res Pract 2011: 748031. [Crossref]

17. Gan TJ (2002) Postoperative nausea and vomiting--can it be eliminated? JAMA 287: 1233-1236. [Crossref]

Copyright: (C2016 González-Melado FJ. This is an open-access article distributed under the terms of the Creative Commons Attribution License, which permits unrestricted use, distribution, and reproduction in any medium, provided the original author and source are credited. 